\title{
The Construction and Practice of Tourism Innovation Entrepreneurship Education System in the New Era
}

\author{
Su Jie \\ Guizhou University of Finance and Economics, Guiyang, Guizhou, China, 550004
}

Keywords: tourism; innovation \& entrepreneurship education system; tourism talents

\begin{abstract}
In the new era, innovation and entrepreneurship education has become more and more important in the education and teaching of colleges and universities. Based on the innovation and entrepreneurship practice teaching of tourism management specialty, this paper aims to enhance the innovation and entrepreneurship ability of undergraduates and explores innovation and entrepreneurship education from the aspects of the integration of entrepreneurial ideas and personnel training systems, curriculum integration, teacher integration, and the combination of fusion strategies. With the deep integration of tourism management professional education, a talent training system is established. The teaching process is gradually integrated to establish a scientific education method of innovation and entrepreneurship practice, and improve the professional quality of innovation and entrepreneurship of college students.
\end{abstract}

\section{Introduction}

At present, China's domestic and outbound tourists, domestic tourism consumption, and overseas tourism consumption are all ranked first in the world, and have become the world's largest tourism market [1]. China has entered the era of mass tourism, with tourism constantly emerged in new business and new fields. The tourism development trend of the demand for quality is in urgent need of a large number of skilled technical talents, who have international vision, profound cultural background and strong creativity, and strong service awareness. According to the needs of the economic society and the development of the industry, there are more and more factors that need to be considered in the professional construction of colleges for innovation and entrepreneurship education [2]. However, the deep integration of innovation and entrepreneurship education and professional education in colleges also requires a long process of exploration. Tourism management as an application-oriented discipline requires the systematic design of innovation and entrepreneurship education integrated into professional education. In the process of training innovative talents for tourism, it is necessary to pay attention to the training of theoretical knowledge and professional skills, and also to strengthen the awareness of innovation and entrepreneurship in the daily teaching process in order to achieve the goal of innovation and entrepreneurship training. The cultivation of tourism innovation and entrepreneurial talents must promote the reform of the talent cultivation model through the integration of entrepreneurial ideas and personnel training systems, curriculum integration, and integration of teachers.

\section{The Status Quo of Education Management System for Tourism Management}

\subsection{Inadequate talent training system}

There is a lack of understanding of the future trends in the individualization and diversification of tourism products, lack of understanding of the innovation, which enhances the vitality and attractiveness of tourism, and the separation of professional education from innovation and entrepreneurship education. Students lack of innovation and entrepreneurship, the low proportion of participating in the practice of entrepreneurship, the low starting point and poor growth of the enterprise, is particularly weak in the adoption of new technology and the development of new markets, which cannot meet the demands of the tourism industry for innovation and entrepreneurship. 


\subsection{Insufficient depth of talent training system}

There is lack of the big tourism concept, and has not yet emerged from the thinking mode of a single industry and the traditional tourism industry. And it has not accurately grasped the characteristics and laws of high degree of linkage, strong openness, and long industry chain, without a comprehensive understanding of China's tourism industry to promote harmony between human and nature, human and human harmony. There is no deep understanding of the application prospect of high technology, especially information technology in the tourism industry. College-enterprise cooperation is low-level and shallow, and the carrier of practice is small and scattered, lagging behind the development trend of technological innovation, product innovation, and model innovation in the tourism industry.

\section{Problems in Tourism Management and Entrepreneurial Education System}

\subsection{Lack of skill training for entrepreneurship}

Colleges are faced with pressures such as the introduction of talent, the enrollment expansion of the students, the expansion of the infrastructure, the evaluation of the undergraduate and so on. It is still in the experiment to improve the training program, and the construction of a complete practical training system, training of students' innovative and entrepreneurial capabilities are still in the experiment, which requires long-term practice to be constantly updated and improved. The tourism management major is limited by professionals, training systems, hardware facilities and policy support. Students mainly focus on theoretical education, and have not kept up with various practical skills. The practical skills of students' hands-on ability, the perception ability to the industry, and the ability to innovate have not reached a high level. And students' own preparation for entrepreneurship is seriously inadequate.

\subsection{Lack of necessary platform for entrepreneurship}

Colleges lack long-term accumulation in the early period, and there are still deficiencies in the cooperation and connection with the industry [3]. Therefore, there are many problems in aspects of cooperation between colleges and enterprises, such as insufficient levels, inexperienced direction choices, unclear practical goals, and imperfect platforms. The entrepreneurship education system for tourism management professionals needs to establish a good platform with hotels, travel agencies, travel planning companies, tourist attractions, OTA companies and many other aspects. The tourism management majors of newly-built undergraduate colleges are selected in practical training bases still have problems, such as insufficient quantity and insufficient quality, which has become the biggest obstacle to students' access to the industry. At the same time, colleges failed to support students innovation and entrepreneurship programs through platforms such as the Challenge Cup and the Student Entrepreneurship Practice Program. Through these platforms, students can form entrepreneurial awareness, contact the industry's latest ideas, and cultivate innovative entrepreneurial skills in the theoretical learning process, which is the foundation for innovation and entrepreneurship.

\subsection{Lack of college support for entrepreneurship}

Many undergraduate colleges and universities have received less support, because as a subject of tourism management, it currently belong to the specialty which is under the control of Ministry of Education, which controls the number of enrollment and the upgrading of the specialty to the undergraduate program to limit its development. These restrictions have had a relatively unfavorable impact on the long-term development of the tourism management profession. Engineering or comprehensive colleges and universities will focus on engineering or science majors that can produce results. The support for liberal arts majors is far less than that of engineering majors, resulting in the engineering profession infringing on the enrollment numbers, development funding, and supports that tourism professionals should have. Such phenomenon have made it difficult for the tourism 
professional entrepreneurship training system to be constructed.

\subsection{Unclear entrepreneurship goals}

Colleges do not have long-term accumulated experience in the formulation of training plans. They also need to be constantly revised in the long-term practice of the colleges themselves so that they can continuously improve. The imperfections of training programs cause teachers and students to have unclear goals for entrepreneurship training. . For the establishment of a complete entrepreneurial education system, it requires a long period of continuous trials to establish a multi-faceted, multi-leveled, fully supported entrepreneurship education system that combines both in and off-campus training.

\section{Countermeasures for the Construction of Tourism Management Entrepreneurship Education System}

\subsection{Build a dual-creation training platform}

Establish a platform for fostering innovation and entrepreneurship within and outside the campus that meets the development law of students' innovation and entrepreneurship. The on-campus platform is divided into basic level and training level. The off-campus platform is divided into activity level and practical level. The carrier and hierarchy of the two platforms are upgraded and complement each other.

The basic level takes innovation and entrepreneurship courses, professional courses, and innovation and entrepreneurship lectures as the carrier to reconstruct the modular curriculum system [4]. The curriculum development and teaching implementation focuses on the student's foresighted grasp of the expertise, skills, and methods of tourism employment and entrepreneurship. The training level is based on comprehensive tourism training projects, entrepreneurship incubation, community activities, and college competitions, relying on open campus training bases and college students' business incubation bases to promote students' professional identity and responsibility in the process of tourism service innovation. The activity level is based on a variety of innovation and entrepreneurship competitions, skill competitions, and thematic social practices. It is based on a large platform outside the college to enhance students' professional qualities and temper their will and quality. The practical level is based on internships and self-employment. It focuses on students' ability to create and solve problems, and enables students to win wider frontier vision and broader development space by independently responding to a wide range of job challenges and changing work options.

\subsection{Integrate production \& education, dual creation, and cultural integration}

The implementation of integration of production and education, dual integration, and integration of culture and travel, will help improve the training of tourism professionals, achieve high-end guidance of tourism professionals, and enhance the tourism professional students more in-depth service capabilities. Integrating production and education, to meet the demand for development. Demand-oriented, to play the role of industry organizations actively, in-depth exploration of both colleges and society resources, the state-owned enterprises and colleges collaborate to educate people, relying on a variety of college-enterprise cooperation models such as modern apprenticeship, title ordering, technical vocational training. Developing talented personnel training to meet the diverse needs of companies for talents and improve service development capabilities.

\subsection{Implement professional genealogy project based on specialty}

Use the perspectives and methods of genealogy to compile career genealogy spectrum, extend the spectrum of industry development, professional development spectrum, student growth spectrum, and development spectrum of professional group. Using time series as a clue and focus on the interactive growth relationship among regions, industries, and professionals. Tracking the trajectory and trends of regional industrial development and professional evolution, and clarifying the context 
of the symbiotic development of regional industries and professions. Through the promotion of career lines, students can understand the service characteristics of the tourism industry, clarify the rules for the growth of tourism technology and skilled personnel, and enhance job glory, sense of professional mission and social responsibility.

\subsection{Construct tourism management innovation and entrepreneurship curriculum system}

According to the training objectives of tourism innovation and entrepreneurship, the curriculum system of innovation and entrepreneurship education is constructed. The foundation level is based on the general education, the core level is based on the professional quality, and the promotion level with the core of professional skills, the development level with the goal ability as the goal, the construction of the professional curriculum system, and the promotion of the students professionalism. At the same time, in the course of professional education, the content of quality education in the innovation and entrepreneurship education is gradually integrated into the process, in order to complete the cultivation of students' innovative and entrepreneurial ability.

\section{Summary}

Innovation and entrepreneurship education and tourism management personnel training system, the integration of professional courses and teachers and other aspects, the construction of a new tourism management professional education system, will change the traditional teaching concepts and teaching methods, and is more prominent students' independent learning and practical learning, and help cultivate students to create a new entrepreneurial consciousness. In the professional education system, the integration of innovation and entrepreneurship education concept can promote the students to master the basic knowledge of innovation and entrepreneurship, and organize the students of tourism management majors to participate in social practice activities and various kinds of innovative entrepreneurship competitions actively, and integrate the innovation and entrepreneurship education with the professional training system and curriculum construction, So as to improve the teaching and learning ability of innovation and entrepreneurship, and achieve a new teaching mode of integration of innovation and entrepreneurship education and professional education.

\section{References}

[1] Wang Xinyue, Liu Erlian. The current situation and countermeasures of entrepreneurship education for college students majoring in tourism management[J]. Vocational Technology, 2016 (9), p.30

[2] Hao Jie, Wu Aihua, Hou Yongfeng. The construction of the innovation and entrepreneurship education system in the United States and its inspiration[J]. Research in Higher Education of Engineering, 2016 (2), p.7

[3] Cheng Bing, Zhao Xia. Under the new normal state, the problems and countermeasures for the cultivation of college students majoring in tourism management in innovation and entrepreneurship[J]. Journal of Hechi University, 2015 (4), p.19

[4] Wang Zhanren, the system structure and theoretical value of broad-spectrum innovation and entrepreneurship education [J]. Education Research, 2015 (5), p.56 